\title{
Effects of telmisartan on vascular endothelial function, inflammation and insulin resistance in patients with coronary heart disease and diabetes mellitus
}

\author{
TAO CHEN, JIEYONG XING and YANSHAO LIU \\ Department of Cardiovascular Medicine, Zhangqiu Hospital of \\ Traditional Chinese Medicine, Jinan, Shandong 250200, P.R. China
}

Received July 13, 2017; Accepted November 1, 2017

DOI: 10.3892/etm.2017.5451

\begin{abstract}
The aim of the present study was to investigate the effects of telmisartan on vascular endothelial functions, inflammatory factors and insulin resistance of coronary heart disease patients complicated with diabetes mellitus. In total, 80 coronary heart disease patients complicated with type 2 diabetes mellitus, admitted and treated in the Zhangqiu Hospital from January 2016 to March 2017 were enrolled in the study. Each patient was randomly assigned to an observation $(n=40)$ or a control group $(n=40)$ using a random number table. Conventional symptomatic and supporting therapies were administered to all the patients in the two groups for 12 consecutive weeks, while additional telmisartan was given only to patients in the observation group. Markers of glucose metabolism, vascular endothelial function and inflammation were determined before and after intervention, to compare averages between groups. Results showed the levels of fasting blood glucose and blood glucose in the observation group were significantly lower than those in the control group $(\mathrm{p}<0.05)$ after 4 weeks of treatment. The levels of HOMA-IR in the observation group were clearly improved compared to those in the control group during the same period $(\mathrm{p}<0.05)$. After the intervention, the levels of FINS and HOMA-IR in the observation group improved significantly more compared with those in the control group $(\mathrm{p}<0.05)$, while the levels of tumor necrosis factor- $\alpha$ (TNF- $\alpha)$, interleukin-6 (IL-6) and C-reactive protein (CRP) were much lower than those in the control group $(\mathrm{p}<0.05)$. Furthermore, at the 4 th, 8 th and 12 th week after starting the treatment, the
\end{abstract}

Correspondence to: Dr Yanshao Liu, Department of Cardiovascular Medicine, Zhangqiu Hospital of Traditional Chinese Medicine, 1463 Embroidered Water Street, Mingshui Street Office, Jinan, Shandong 250200, P.R. China

E-mail: liuyanshao369@163.com

Key words: telmisartan, coronary heart disease, diabetes mellitus, vascular endothelial function, inflammatory factor, insulin resistance vascular endothelin (ET) levels in the observation group were significantly lower than those in the control group $(\mathrm{p}<0.05)$. In addition, the brachial artery diameters in the basal state were significantly larger than those in the control group $(\mathrm{p}<0.05)$ for the same time-points. Coronary heart disease patients complicated with diabetes mellitus whose treatment includes telmisartan can better regulate their blood glucose, reduce the insulin resistance and body inflammatory responses and improve their vascular endothelial functions.

\section{Introduction}

Coronary heart disease patients complicated with diabetes mellitus may present with declined insulin sensitivity, weakened blood pressure regulating ability, damage to vascular endothelial cells, dysfunction of the fibrinolytic system and increased sterile inflammatory responses, all of which are indicators of disease progression and poor prognosis (1-7). Vascular endothelial cell injury, insulin resistance and increased inflammatory markers have attracted increasing attention in the clinical practice, as core factors for the occurrence and development of simple coronary heart disease or type 2 diabetes mellitus.

Telmisartan, an angiotensin II receptor blocker (ARB), commonly used in the clinic, can improve the function of endothelial cells, reduce oxidative stress responses in the body and alleviate superoxide damage (8). In addition, for patients with diabetes mellitus, telmisartan can inhibit the peroxisome proliferator-activated receptor- $\gamma$ and is used as an agonist to some extent (with clinical effects similar to those of pioglitazone). Therefore, it can substantially improve pancreatic islet blood flow (9), thus reducing the occurrence of insulin resistance.

The focus of the present study was on coronary heart disease patients complicated with diabetes mellitus who were treated with telmisartan. Their vascular endothelial functions, inflammatory factors and insulin resistance markers were obtained to analyze the effects of the treatment.

\section{Materials and methods}

General information. Eighty coronary heart disease patients complicated with type 2 diabetes mellitus, admitted and treated 
in the Zhangqui Hospital from January 2016 to March 2017, participated in the study. All the patients were diagnosed via coronary angiography; type 2 diabetes mellitus was confirmed by glucose tolerance test results. Signed informed consent forms were obtained from all the patients and the Ethics Committee of the Zhangqiu Hospital (Shandong, China) approved the study. Patients complicated with malignant tumors, mental or immune system diseases, as well as patients who had used glucocorticoid and/or immunodepressants over a long period of time, were excluded. The patients were randomly divided into two groups of 40 patients each, using a random number table. There were 25 men and 15 women in the observation group aged from 60 to 83 years, averaging $77.1 \pm 1.1$ years; they had suffered from diabetes mellitus for 5 to 35 years $(23.1 \pm 3.1$ years on average) and from coronary heart disease for 5 to 30 years $(19.2 \pm 1.1$ years on average). In the control group, there were 24 men and 16 women, aged from 60 to 84 years (averaging 77.0 \pm 1.0 years); they had diabetes mellitus for 5 to 35 years ( $23.0 \pm 3.0$ years on average) and coronary heart disease for 5 to 30 years $(19.1 \pm 1.2$ years on average). In terms of the general information of patients, differences in sex, age and length of disease between the two groups were not statistically significant ( $\mathrm{p}>0.05$ ).

Methods. All the patients received conventional treatments such as antiplatelet, anticoagulation, lipid lowering, vasodilation and blood pressure drugs for coronary heart disease; and dietary control, exercise therapy and oral hypoglycemic drugs for diabetes mellitus. Moreover, insulin was injected subcutaneously in selective cases, it was generally recommended to maintain the level of fasting blood glucose at $<7.0 \mathrm{mmol} / 1$ and that of blood glucose $2 \mathrm{~h}$ after a meal at $<11.1 \mathrm{mmol} / \mathrm{l}$ and to adjust the glycosylated hemoglobin to $7.0 \%$ or lower. The patients received health education to support diabetes mellitus treatment. Additionally, telmisartan (NMPN H20041082; Shanghai Sine-Tianping Pharmaceuticals, Shanghai, China) was given to patients in the observation group $(80 \mathrm{mg}$ telmisartan orally once a day each morning for 12 consecutive weeks).

Observation variables. The two groups were treated for 12 consecutive weeks and relevant markers were measured at different time-points (before treatment and 4, 8 and 12 weeks after treatment). The fasting blood glucose, homeostasis model assessment of insulin resistance (HOMA-IR), vascular endothelin (ET) and changing trend of brachial artery diameter in the basal state of the patients in the two groups in the intervention process were recorded. Additionally, the levels of blood glucose $2 \mathrm{~h}$ after a meal, the fasting serum insulin (FINS) and the levels of inflammation-associated cytokines of the patients in the two groups after intervention were compared.

Evaluation methods and criteria. A Hitachi 7080 Automatic Biochemical Tester and Analyzer was used to examine the fasting blood glucose and the blood glucose $2 \mathrm{~h}$ after a meal (the normal value for fasting blood glucose was 3.9-6.1 mmol/1 and that for blood glucose $2 \mathrm{~h}$ after meal was $<7.8 \mathrm{mmol} / \mathrm{l}$ ).

The double-antibody single-step sandwich method was used to detect the tumor necrosis factor- $\alpha$ (TNF- $\alpha$ ) and interleukin-6 (IL-6) levels, and the normal reference value for TNF- $\alpha$ was 5 to $100 \mathrm{ng} / \mathrm{l}$ and that for IL-6 56.4 to $150.3 \mathrm{ng} / \mathrm{l}$.
Immunity transmission turbidity was used for the detection of C-reactive protein (CRP) in plasma (normal $\leq 10 \mathrm{mg} / \mathrm{l}$ ).

A Beckman-Coulter Access DxI 800 Type chemiluminescent analyzer (Beckman-Coulter, Brea, CA, USA) was used to measure the FINS, and that value was used in a formula to obtain the HOMA-IR = [fasting blood glucose $(\mathrm{mmol} / \mathrm{l}) \mathrm{x}$ FINS (mU/1)]/22.5. The normal range for FINS was 3.0-24.9 U/ml and the normal value of HOMA-IR was 1 .

Radioimmunoassay was applied to examine vascular ET and the normal reference value was $50.8 \pm 7.58 \mathrm{pg} / \mathrm{l}$. For detection of the brachial artery diameter in the basal state, all the patients were examined at $24^{\circ} \mathrm{C}$ and a Philips HD11 XE Color Doppler ultrasonic detector was used. During the detection, patients were required to lie in the supine position with the abduction of tested upper limb at $15^{\circ}$, and the ultrasonic probe was placed $5-15 \mathrm{~cm}$ above the elbow to detect the brachial artery and the recorded parameters included the vertical dimension of the brachial artery intima (average of 3 continuous measurements at the end of vasorelaxation).

Statistical analysis. Statistical Product and Service Solutions (SPSS) 19.0 software (SPSS, Inc., Chicago, IL, USA) was used. The measurement data were presented as mean \pm standard deviation (SD). The t-test was used to compare the means of two groups, and the $\chi^{2}$ test was applied to compare the rates between groups. $\mathrm{P}<0.05$ was considered to indicate a statistically significant difference.

\section{Results}

Comparison of changing fasting blood glucose trends between the two groups in the intervention process. The average level of fasting blood glucose in the observation group was $16.6 \pm 2.1 \mathrm{mmol} / \mathrm{l}$ prior to the intervention, $13.2 \pm 2.0 \mathrm{mmol} / \mathrm{l}$ in the 4 th week after intervention, then $10.1 \pm 1.8 \mathrm{mmol} / \mathrm{l}$ in the 8th week after intervention and $5.2 \pm 1.0 \mathrm{mmol} / \mathrm{l}$ in the $12 \mathrm{th}$ week after intervention. For comparison the average level of fasting blood glucose in the control group started at $16.7 \pm 2.1 \mathrm{mmol} / 1$ before intervention, decreased to $14.7 \pm 1.9$, then to $11.3 \pm 1.7$ and finally $8.7 \pm 1.1 \mathrm{mmol} / \mathrm{l}$ for the same time-points after intervention as for the observation group. The difference between the average values of the two groups before the intervention was not significant. However, from the 4th week after intervention, the levels of fasting blood glucose in the observation group were always significantly lower than those in the control group at the same time-points $(\mathrm{p}<0.05)($ Fig. 1).

Comparisons of average fasting blood glucose and blood glucose $2 \mathrm{~h}$ after meal in two groups after the intervention. The average level of blood glucose $2 \mathrm{~h}$ after meal in the observation group was siginificantly lower than that in the control group after the intervention $(\mathrm{p}<0.05)$. Values of fasting blood glucose and blood glucose $2 \mathrm{~h}$ after a meal are shown in Table I.

Comparison of trends of HOMA-IR values in the two groups during the intervention process. Prior to treatment, the average HOMA-IR value in the control group was $2.01 \pm 0.08$, $1.98 \pm 0.06$ in the 4 th week after beginning of the treatment, $1.94 \pm 0.04$ in the 8 th week and $1.88 \pm 0.02$ in the 12 th week. The same HOMA-IR values in the observation group were 


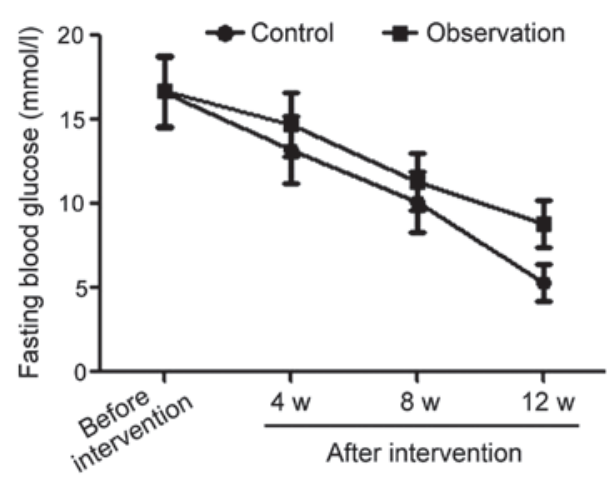

Figure 1. Changing trends of fasting blood glucose in the two groups in the intervention process.

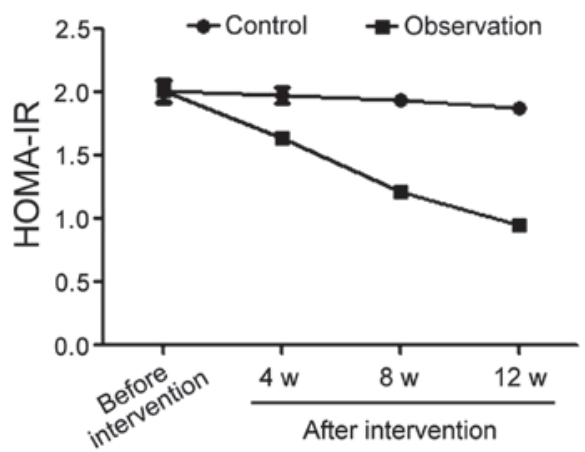

Figure 2. Comparison of trends of HOMA-IR values during the intervention process in the two groups. HOMA-IR, homeostasis model assessment of insulin resistance.

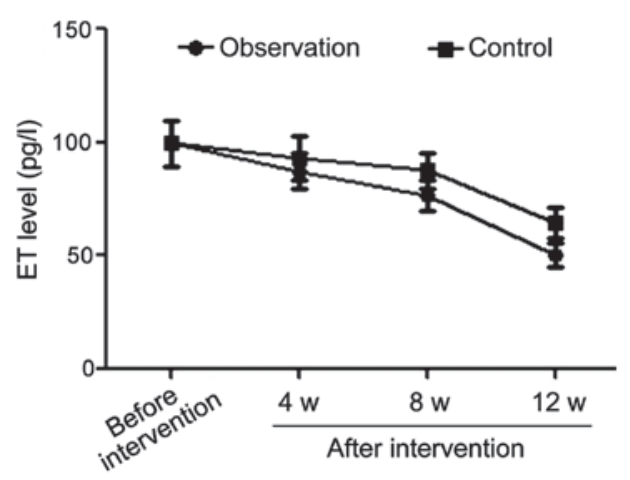

Figure 3. Comparisons of ET changes in the two groups at different time-points of intervention. ET, endothelin.

$2.01 \pm 0.09$ before treatment and $1.64 \pm 0.03,1.21 \pm 0.02$ and $0.95 \pm 0.01$ in the 4 th, 8 th and 12 th week after intervention, respectively. The comparison of the HOMA-IR averages before intervention in the two groups yielded no statistically significant difference. From the 4th week after the beginning of treatment, the levels of HOMA-IR of patients in the observation group were significantly better than those of patients in the control group during the same period $(\mathrm{p}<0.05)$ (Fig. 2).

Comparisons of average FINS and HOMA-IR values in the two groups after intervention. The levels of FINS and HOMA-IR in the observation group were significantly
Table I. Comparisons of fasting blood glucose and blood glucose $2 \mathrm{~h}$ after meal in the two groups after intervention $(\mathrm{mmol} / \mathrm{l}$, mean $\pm \mathrm{SD})$.

\begin{tabular}{lcc}
\hline Variables & $\begin{array}{c}\text { Fasting blood } \\
\text { glucose }\end{array}$ & $\begin{array}{c}\text { Blood glucose } \\
\text { 2 h after meal }\end{array}$ \\
\hline Observation group & $5.2 \pm 1.0$ & $7.0 \pm 1.4$ \\
Control group & $8.7 \pm 1.1$ & $14.0 \pm 2.1$ \\
t-test & 14.890 & 17.541 \\
P-value & $<0.001$ & $<0.001$ \\
\hline
\end{tabular}

Table II. Comparisons of FINS and HOMA-IR after intervention in the two groups (mean $\pm \mathrm{SD})$.

\begin{tabular}{lcc}
\hline Variables & HOMA-IR & FINS (mU/l) \\
\hline Observation group & $0.95 \pm 0.01$ & $4.26 \pm 1.20$ \\
Control group & $1.88 \pm 0.02$ & $8.35 \pm 1.61$ \\
t-test & 263.044 & 12.882 \\
P-value & $<0.001$ & $<0.001$ \\
\hline
\end{tabular}

FINS, fasting serum insulin; HOMA-IR, homeostasis model assessment of insulin resistance.

Table III. Comparisons of inflammatory factors after intervention in the two groups (mean $\pm \mathrm{SD}$ ).

\begin{tabular}{lccr}
\hline Variables & $\begin{array}{c}\text { TNF- } \alpha \\
(\mathrm{ng} / \mathrm{l})\end{array}$ & $\begin{array}{c}\mathrm{IL}-6 \\
(\mathrm{ng} / \mathrm{l})\end{array}$ & \multicolumn{1}{c}{$\begin{array}{c}\mathrm{CRP} \\
(\mathrm{ng} / \mathrm{l})\end{array}$} \\
\hline Observation group & $100.3 \pm 5.1$ & $79.0 \pm 3.1$ & $6.1 \pm 0.2$ \\
Control group & $251.6 \pm 11.0$ & $125.0 \pm 5.0$ & $11.1 \pm 1.5$ \\
t-test & 78.922 & 49.452 & 20.897 \\
P-value & $<0.001$ & $<0.001$ & $<0.001$ \\
\hline
\end{tabular}

TNF- $\alpha$, tumor necrosis factor- $\alpha$; IL-6, interleukin-6; CRP, C-reactive protein.

improved compared with those in the control group after the beginning of treatment $(\mathrm{p}<0.05)$ (Table II).

Comparisons of average levels of inflammatory factors in the two groups after intervention. Average levels of inflammatory cytokines, including TNF- $\alpha$, IL-6 and CRP in the observation group were lower than those in the control group $(\mathrm{p}<0.05)$ (Table III).

Comparisons of ET changes in the two groups at different time-points of intervention. The differences in ET levels between the the two groups before intervention were not statistically significant. However, once treatment started, the ET levels in the observation group were significantly lower than those in control group in the 4th, 8 th and 12th week after intervention $(\mathrm{p}<0.05)$ (Table IV and Fig. 3). 
Table IV. Comparisons of ET changes in the two groups at different time-points during treatment $(\mathrm{pg} / \mathrm{l}$, mean $\pm \mathrm{SD})$.

\begin{tabular}{lcccc}
\hline Variables & $\begin{array}{c}\text { Before } \\
\text { treatment } \\
\text { onset }\end{array}$ & $\begin{array}{c}4 \text { weeks } \\
\text { after } \\
\text { treatment } \\
\text { onset }\end{array}$ & $\begin{array}{c}8 \text { weeks } \\
\text { after } \\
\text { treatment } \\
\text { onset }\end{array}$ & $\begin{array}{c}12 \text { weeks } \\
\text { after } \\
\text { treatment } \\
\text { onset }\end{array}$ \\
\hline $\begin{array}{l}\text { Observation } \\
\text { group }\end{array}$ & $99.8 \pm 10.1$ & $87.4 \pm 7.8$ & $76.4 \pm 6.9$ & $50.2 \pm 5.2$ \\
$\begin{array}{l}\text { Control } \\
\text { group }\end{array}$ & $99.7 \pm 10.0$ & $92.9 \pm 9.6$ & $87.8 \pm 7.9$ & $64.3 \pm 6.8$ \\
$\begin{array}{l}\text { t-test } \\
\text { P-value }\end{array}$ & 0.044 & 2.812 & 6.874 & 10.417 \\
\hline
\end{tabular}

ET, endothelin.

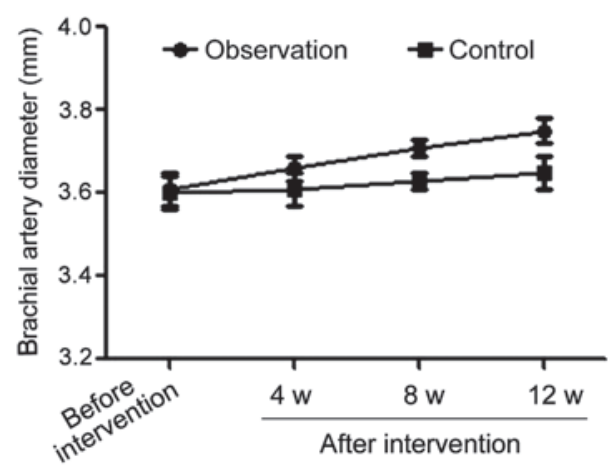

Figure 4. Comparisons of average values of brachial artery diameters in the basal state in two groups during the intervention process.

Table V. Comparisons of brachial artery diameters in the basal state in the two groups during the intervention process $(\mathrm{mm}$, mean $\pm \mathrm{SD})$.

\begin{tabular}{lcccc}
\hline Variables & $\begin{array}{c}\text { Before } \\
\text { treatment } \\
\text { onset }\end{array}$ & $\begin{array}{c}4 \text { weeks } \\
\text { after } \\
\text { treatment } \\
\text { onset }\end{array}$ & $\begin{array}{c}8 \text { weeks } \\
\text { after } \\
\text { treatment } \\
\text { onset }\end{array}$ & $\begin{array}{c}12 \text { weeks } \\
\text { after } \\
\text { treatment } \\
\text { onset }\end{array}$ \\
\hline $\begin{array}{l}\text { Observation } \\
\text { group }\end{array}$ & $3.61 \pm 0.04$ & $3.66 \pm 0.03$ & $3.71 \pm 0.02$ & $3.75 \pm 0.03$ \\
$\begin{array}{l}\text { Control } \\
\text { group }\end{array}$ & $3.60 \pm 0.04$ & $3.61 \pm 0.04$ & $3.63 \pm 0.02$ & $3.65 \pm 0.04$ \\
t-test & 1.118 & 6.325 & 17.889 & 12.649 \\
P-value & 0.267 & $<0.001$ & $<0.001$ & $<0.001$ \\
\hline
\end{tabular}

Comparisons of brachial artery diameters in the basal state in the two groups during the intervention process. Comparison of the brachial artery diameters in the basal state before the beginning of treatment in both groups showed the difference was not statistically significant. However, once treatment started, the brachial artery diameters in the basal state in observation group were significantly larger than those in the control group $(\mathrm{p}<0.05)$ at all time-points during treatment (Table V and Fig. 4).

\section{Discussion}

For coronary heart disease patients complicated with diabetes mellitus, hyperglycemia, hyperlipidemia, insulin resistance, hyperinsulinemia, increase of inflammatory markers, injury of vascular endothelial cells and blood pressure surges constitute risk factors associated with further aggravation of atherosclerosis (10-12). Telmisartan, which belongs to the family of terminal angiotensin 1 receptor selective blockers (13), can regulate vascular tone by blocking the angiotensin downstream cascade without affecting the levels of bradykinin and prostacyclin in the body; therefore, it is suitable for clinical treatment of coronary heart disease complicated with diabetes mellitus.

This study was carried out among coronary heart disease patients complicated with diabetes mellitus; conventional symptomatic and supporting therapies were used in both the control and observation groups, while treatment combined with telmisartan was used exclusively in the observation group. By monitoring different variables during treatment, it was found that, the levels of fasting blood glucose in the observation group were significantly lower, and the levels of HOMA-IR clearly improved compared to those in the control group. This suggests that, for coronary heart disease patients complicated with diabetes mellitus, treatment in combination with telmisartan can better regulate their blood glucose and HOMA-IR levels and is more conducive to the control of diabetes mellitus. In addition, the level of blood glucose $2 \mathrm{~h}$ after a meal in the observation group was lower than that in the control group, and the levels of FINS and HOMA-IR in the observation group were significantly improved compared to those in the control group. This provides further evidence that the combined treatment with telmisartan is of great value in effectively regulating the blood glucose and improving insulin resistance in these patients. Moreover, our findings showed lower levels of TNF- $\alpha$, IL-6 and CRP in the observation group and thus the efficacy of the approach for reducing the sterile inflammatory responses in the body that increase the severity of diabetes mellitus and/or coronary heart disease and carry a poor prognosis was also revealed. Finally, by comparing the changes of ET at different time-points and the brachial artery diameters in the basal state in the two groups, we showed the values for the two variables were significantly better in the observation group. Our results indicate the telmisartan combination treatment was effective for lowering the levels of angiotensin, improving the vascular endothelial functions and dilating blood vessels as evidenced by other studies $(14,15)$. The fact that telmisartan can inhibit the sterile inflammatory responses in the body may be related to its blocking of the angiotensin II receptor (15). The drug is also known to activate the peroxisome proliferator-activated receptor- $\gamma$ and reduce vasoconstriction (16). Furthermore, its effects regulating the blood glucose level in patients with diabetes mellitus can be explained by its ability to improve lipid metabolism in the body, alleviate body oxidative stress responses (17), reduce damage to blood vessels caused by oxygen-free radicals (18), lower the ET level, improve vasodilation functions and relieve insulin resistance (19).

In conclusion, our findings support a conventional treatment in combination with telmisartan for coronary heart disease patients complicated with diabetes mellitus, as this 
approach can better regulate blood glucose levels, reduce insulin resistance and body inflammatory responses and improve the vascular endothelial functions in patients.

\section{References}

1. Park S, Kario K, Park CG, Huang QF, Cheng HM, Hoshide S, Wang JG and Chen $\mathrm{CH}$; Characteristics On the ManagEment of Hypertension in Asia-Morning Hypertension Discussion Group (COME Asia MHDG): Target blood pressure in patients with diabetes: Asian perspective. Yonsei Med J 57: 1307-1311, 2016

2. Bays H, Gao P, Völker B, Mattheus M, Ruilope LM and Zhu D: Efficacy of single-pill combination of telmisartan $80 \mathrm{mg}$ and hydrochlorothiazide $25 \mathrm{mg}$ in patients with cardiovascular disease risk factors: A prospective subgroup analysis of a randomized, double-blind, and controlled trial. Int J Hypertens 2013: 749830, 2013.

3. Verdecchia P, Dagenais G, Healey J, Gao P, Dans AL, Chazova I, Binbrek AS, Iacobellis G, Ferreira R, Holwerda N, et al; Ongoing Telmisartan Alone and in Combination With Ramipril Global Endpoint TrialTelmisartan Randomized AssessmeNt Study in ACE iNtolerant subjects with cardiovascular Disease Investigators: Blood pressure and other determinants of new-onset atrial fibrillation in patients at high cardiovascular risk in the Ongoing Telmisartan Alone and in Combination With Ramipril Global Endpoint Trial/Telmisartan Randomized Assessment Study in ACE intolerant subjects with cardiovascular Disease studies. J Hypertens 30: 1004-1014, 2012.

4. Takagi $\mathrm{H}$ and Umemoto $\mathrm{T}$ : Telmisartan increases adiponectin levels: A meta-analysis and meta-regression of randomized head-to-head trials. Int J Cardiol 155: 448-451, 2012.

5. Nilsson PM: Target blood pressure in diabetes patients with hypertension - what is the accumulated evidence in 2011? J Zhejiang Univ Sci B 12: 611-623, 2011.

6. Hong SJ, Choi SC, Ahn CM, Park JH, Kim JS and Lim DS: Telmisartan reduces neointima volume and pulse wave velocity 8 months after zotarolimus-eluting stent implantation in hypertensive type 2 diabetic patients. Heart 97: 1425-1432, 2011.

7. Toyama K, Nakamura T, Kataoka K, Yasuda O, Fukuda M, Tokutomi Y, Dong YF, Ogawa $\mathrm{H}$ and Kim-Mitsuyama S: Telmisartan protects against diabetic vascular complications in a mouse model of obesity and type 2 diabetes, partially through peroxisome proliferator activated receptor- $\gamma$-dependent activity. Biochem Biophys Res Commun 410: 508-513, 2011.

8. Cowan BR, Young AA, Anderson C, Doughty RN, Krittayaphong R, Lonn E, Marwick TH, Reid CM, Sanderson JE, Schmieder RE, et al; ONTARGET Investigators: Left ventricular mass and volume with telmisartan, ramipril, or combination in patients with previous atherosclerotic events or with diabetes mellitus (from the ONgoing Telmisartan Alone and in Combination With Ramipril Global Endpoint Trial [ONTARGET]). Am J Cardiol 104: 1484-1489, 2009.

9. Chang WT, Cheng JT and Chen ZC: Telmisartan improves cardiac fibrosis in diabetes through peroxisome proliferator activated receptor $\delta$ (PPAR $\delta$ ): From bedside to bench. Cardiovasc Diabetol 15: 113, 2016.
10. Toma I, Kim PJ, Dash R, McConnell MV, Nishimura D, Harnish P and Yang PC: Telmisartan in the diabetic murine model of acute myocardial infarction: Dual contrast manganese-enhanced and delayed enhancement MRI evaluation of the peri-infarct region. Cardiovasc Diabetol 15: 24-25, 2016.

11. Chen AX, Jerums G, Baqar S, Lambert E, Somarajah G, Thomas G, O'Callaghan C, MacIsaac RJ and Ekinci EI: Short-term dietary salt supplementation blunts telmisartan induced increases in plasma renin activity in hypertensive patients with type 2 diabetes mellitus. Clin Sci (Lond) 129: 415-422, 2015.

12. Chaudagar KK and Mehta AA: Effect of telmisartan on VEGF-induced and VEGF-independent angiogenic responsiveness of coronary endothelial cells in normal and streptozotocin (STZ)-induced diabetic rats. Clin Exp Hypertens 36: 557-566, 2014.

13. Rizos CV, Liberopoulos EN, Tellis K, DiNicolantonio JJ, Tselepis AD and Elisaf MS: Combining rosuvastatin with angiotensin-receptor blockers of different PPAR $\gamma$-activating capacity: Effects on high-density lipoprotein subfractions and associated enzymes. Angiology 66: 36-42, 2015.

14. Antoniou T, Camacho X, Yao Z, Gomes T, Juurlink DN and Mamdani MM: Comparative effectiveness of angiotensin-receptor blockers for preventing macrovascular disease in patients with diabetes: A population-based cohort study. CMAJ 185: 1035-1041, 2013.

15. Michel MC, Foster C, Brunner HR and Liu L: A systematic comparison of the properties of clinically used angiotensin II type 1 receptor antagonists. Pharmacol Rev 65: 809-848, 2013.

16. Dehghan M, Mente A, Teo KK, Gao P, Sleight P, Dagenais G, Avezum A, Probstfield JL, Dans T and Yusuf S; Ongoing Telmisartan Alone and in Combination With Ramipril Global End Point Trial (ONTARGET)/Telmisartan Randomized Assessment Study in ACEI Intolerant Subjects With Cardiovascular Disease (TRANSCEND) Trial Investigators: Relationship between healthy diet and risk of cardiovascular disease among patients on drug therapies for secondary prevention: A prospective cohort study of 31546 high-risk individuals from 40 countries. Circulation 126: 2705-2712, 2012.

17. Volpe M: Preventing cardiovascular events with angiotensin II receptor blockers: A closer look at telmisartan and valsartan. Expert Rev Cardiovasc Ther 10: 1061-1072, 2012.

18. Guo Z, Zhang R, Li J and Xu G: Effect of telmisartan on the expression of adiponectin receptors and nicotinamide adenine dinucleotide phosphate oxidase in the heart and aorta in type 2 diabetic rats. Cardiovasc Diabetol 11: 94-111, 2012.

19. Kappert K, Böhm M, Schmieder R, Schumacher H, Teo K, Yusuf S, Sleight P and Unger T; ONTARGET/TRANSCEND Investigators: Impact of sex on cardiovascular outcome in patients at high cardiovascular risk: Analysis of the Telmisartan Randomized Assessment Study in ACE-Intolerant Subjects With Cardiovascular Disease (TRANSCEND) and the Ongoing Telmisartan Alone and in Combination With Ramipril Global End Point Trial (ONTARGET). Circulation 126: 934-941, 2012.

This work is licensed under a Creative Commons Attribution-NonCommercial-NoDerivatives 4.0 International (CC BY-NC-ND 4.0) License. 